\title{
Antifungal activity of Terminalia chebula fruit extracts
}

\author{
P. Venkatachalam* and C.V. Chittibabu \\ Department of Plant Biology and Plant Biotechnology, Presidency College (Autonomous), Chennai-600005, Tamilnadu, \\ India
}

Received: September 27, 2020 Revised: December 08, 2020 Accepted: December 11, 2020 Published: December 19, 2020

\section{*Corresponding Author:}

P. Venkatachalam

Email: pvchalam55@gmail.com KEVwords: Antifungal activity, Terminalia chebula, Candida, Aspergillus, Dermatophytes

\begin{abstract}
The present study was aimed to investigate the anticandidal and antifungal potential of dried fruit extracts of Terminalia chebula against Candida albicans, C. tropicalis C. glabrata, C. krusei, C. parapsilosis, and Aspergillus flavus, A. niger, A. fumigatus, Trichophyton mentagrophytes, T. rubrum, Microsporum gypseum. Phytochemical analysis of methanol extracts of T. chebula dried fruits showed the presence of flavonoids, alkaloids, glycosides, saponins, tannins, terpenoids and steroids. Among the tested four extracts, the methanol extracts of T. chebula dried fruits exhibited the highest antifungal activity and their inhibition zone was ranged between 7.5 to $19.5 \mathrm{~mm}$. MIC and MFC values were between $62.5-250 \mu \mathrm{g} / \mathrm{ml}$ and $250-500 \mu \mathrm{g} / \mathrm{ml}$ respectively. Zone of inhibition $(19.5 \mathrm{~mm})$, MIC $(62.5 \mu \mathrm{g} / \mathrm{ml})$ and MFC $(125 \mu \mathrm{g} / \mathrm{ml})$ values observed in methanolic extracts of T. chebula dried fruits against A. fumigates and T. mentagrophytes. Our findings proved that methanolic extracts of $T$. chebula dried fruits were possessed substantial anticandidal and antifungal properties.
\end{abstract}

\section{INTRODUCTION}

In tribal community, dermal and mucous infections are the most common type of infections occurs due their poor personal hygiene including food habits, sanitation and lacking of clean drinking water. The most common dermal fungal pathogens are belongs to dermatophytes and Candida sp. [1,2]. Among the recent fungal infection case studies, $>90 \%$ infections are due to Candida albicans, which leads to Candidiasis [3]. Due to the affiliations between domesticated animals and humans often end with either ringworm or tinea infections. Dermatophytic species generally grows on the outer surface such as nails, hair and skin on humans as well as domestic animals appendages also. Dermatophytes specifically infest keratin protein present in hair, hooves, beaks and skin. Dermatophyte microbes belong to three genuses such as Trichophyton, Microsporum and Epidermophyton [4].

Another pathogen, Aspergillus fumigates also cause deleterious fungal infections especially in less immunocompetent humans patients which eventually end with Aspergillosis [5,6]. Similarly, immunocompetent individuals are more susceptible towards Cryptococcus neoformans, Candida albicans, Asperillgus fumigatus and Histoplasma capsulatum [7]. Recently, long term antifungal therapies prone to microbial evolution and became a multi drug resistant strain against broad spectrum of antibiotics which currently used in drug therapies against fungal infection [8]. Indeed, conventional antifungal agents from medicinal plants were used as an effective alternative source.

Various human and plant microbes such as Corynebacterium accolans, C. albicans, Staphylococcus aureus and Erwinia carotovora were treated with polyphenolic ellagic acid, gallic acid and corilagin [9]. Terminalia chebula Retzius belongs to the Family Combretaceae which is native to India and Southeast Asia. It is commonly called as black myroblans [10]. This plant popularly used in folk medicine either alone or with other herbs and also used as cardiotonic, denrifrice, stomache tonic, laxative and purgative. T. chebula fruits are used to treat skin infections, diabetes, digestive disorders, burns, and kidney dysfunction and eye diseases $[11,10]$. Thus, the current study was undertaken to analyze the antifungal activity of various solvent extracts of T. chebula dried fruits.

\section{MATERIALS AND METHODS}

\section{Collection and Preparation of Crude Extracts}

The experimental plant Terminalia chebula Retzius (Combretaceae) were collected from Kovilur Panchyath at Javadhu hills of Eastern Ghats (Figure 1) and the fruits were utilized in this study. T. chebula fruits washed with tap water, $10 \%$ of Sodium hypochlorite solution and finally rinsed with distilled water. The dried fruits were grounded finely into powder. In Soxhlet apparatus $\left(>78^{\circ} \mathrm{C}\right), 500 \mathrm{gms}$ of fine powder was mixed 


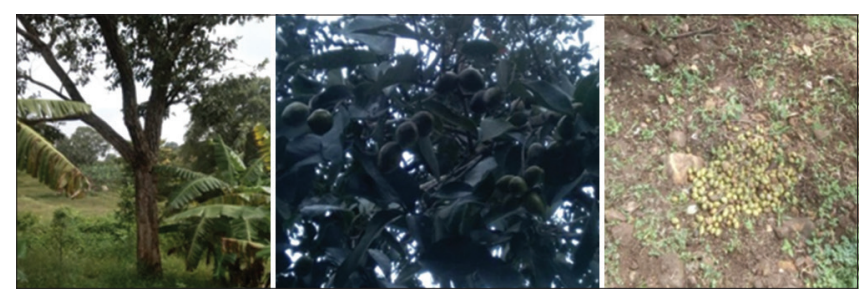

Figure 1: Morphology of Terminalia chebula fruits

with non-polar to polar solvents viz., hexane, ethyl acetate, chloroform and methanol for 72 hours of each solvent. In a rotary evaporator, (Heidolph, Germany) the solvents were evaporated under vacuum and the dried extracts were stored $\left(4^{\circ} \mathrm{C}\right)$.

\section{Phytochemical Screening}

The hexane, ethyl acetate, chloroform and methanolic crude extracts were used for the preparatory phytochemical examination of flavonoids, alkaloids, saponins, glycosides, tannins, steroids and terpenoids [11].

\section{Microorganisms}

The fungal strains viz., Candida albicans, C. glabrata, C. tropicalis, C. parapsilosis, C. krusei, Aspergillus niger, A. flavus, A. fumigatus, Trichophyton rubrum, T. mentagrophytes and Microsporum gypseum were obtained from Christian Medical College (CMC) Vellore, India. Sabouraud Dextrose Agar (SDA), Sabouraud Dextrose Broth (SDB) from Himedia Ltd., (Mumbai) used to study the antifungal activity for yeast and mould fungi.

\section{Antifungal Assays}

\section{Disc diffusion method}

T. chebula dried fruits crude extracts antifungal properties were studied by disc diffusion method [12]. For susceptibility test, $20 \mathrm{ml}$ SDA medium poured into Petri plates for yeast and filamentous fungi. $100 \mu \mathrm{l}$ of fungal suspension containing $10^{6}$ $\mathrm{CFU} / \mathrm{ml}$ and $10^{4}$ spore $/ \mathrm{mL}$ for yeast and mould fungi respectively were inoculated into the media. Under aseptic conditions, sterile (HiMedia) paper disc $(6 \mathrm{~mm})$ were impregnated with $20 \mu \mathrm{l}$ of disparate extract concentrations (1000, 500 and $250 \mu \mathrm{g} / \mathrm{disc})$ dissolved in $10 \%$ DMSO and placed on the agar plates.

For positive control, Amphotericin - B (100units/disc) and Ketoconazole $(10 \mu \mathrm{g} / \mathrm{disc})$ for yeast and Aspergillus, dermatophytes were used and 10\% DMSO used as negative control. Finally, the inoculated plates were incubated for $24-48 \mathrm{~h}$ at $28^{\circ} \mathrm{C}$ for yeast, for $72-96 \mathrm{~h}$ for Aspergillus sp. and 4-7 days with dermatophytes at $30^{\circ} \mathrm{C}$. Inhibition zone was measured in mms.

\section{Determination of Minimum Inhibitory Concentration (MIC)}

T. chebula dried fruit extracts MIC was determined by broth micro dilution technique as recommended by CLSI M27-A3 [13] and M38-A2 [14] for yeasts and filamentous fungi, respectively. The MIC values were analyzed in RPMI-1640 (pH 7.0, Himedia, Mumbai) which is composed of L-glutamine with morpholine propane sulfonic acid (MOPS) without $\mathrm{NaHCO}_{3} .50 \mathrm{mg} / \mathrm{ml}$ $(20 \mu \mathrm{L}$ stock) of crude extracts mixed with $10 \%$ DMSO and dissolved in $980 \mu \mathrm{l}$ of RPMI-1640 medium solution. From this, solutions were two fold serial diluted in the ranges from 500 to $15.7 \mu \mathrm{g} / \mathrm{mL}$. In 96 well microtitre plates, $200 \mu \mathrm{L}$ of solution was poured into first well and then $100 \mu \mathrm{L}$ transferred to the next well containing $100 \mu \mathrm{L}$ of RPMI-1640, and the serially diluted to the other wells.

$100 \mu \mathrm{L}$ of inoculum suspension was transmitted to each well to achieve a concentration of approximately $0.5-2.5 \times 10^{3} \mathrm{CFU} / \mathrm{mL}$ and $0.4-5 \times 10^{4} \mathrm{CFU} / \mathrm{mL}$ for yeasts and filamentous fungi. Without inoculum only sterile water was added for control well. The microtitre plates were incubated for 24-48 hrs at $28^{\circ} \mathrm{C}$ for yeast and for $72-96$ hrs for Aspergillus sp. and 4-7 days with dermatophytes at $30^{\circ} \mathrm{C}$. Growth inhibition of different concentrations of crude extracts on Candida, Aspergillus and dermatophytic strains were compared with control results and the lowest concentration was recorded as MIC.

\section{Determination of Minimum Fungicidal Concentration (MFC)}

From each MIC titre well, SDA plates were inoculated with a loop of samples and then incubated for $24-48 \mathrm{hrs}$ at $28^{\circ} \mathrm{C}$ for yeast and for 72-96hrs for Aspergillus and 4-7 days for dermatophytes at $30^{\circ} \mathrm{C}$. The lowest concentration of the extract which inhibits visible fungal growth after incubation was recorded as MFC.

\section{Statistical Analysis}

A result of statistical analysis was performed by using SPSS software 16.0 version (SPSS Inc., Chicago, IL, USA). The antifungal activity between the crude extracts and their significance were studied by student's t-test and their mean comparison was performed by one-way analysis of variance (ANOVA) and Duncan post hoc test. $P$ value $<0.05$ was considered as statistically significant and the results were expressed as mean $\pm \mathrm{SD}$.

\section{RESULTS}

Hexane, ethyl acetate, chloroform and methanol extracts of T. chebula dried fruits were used to study the phytochemicals such as flavonoids, saponins, alkaloids, glycosides, terpenoids, steroids and tannins. Among the various extracts, methanolic extract of T. chebula dried fruits showed the strong presence of phytochemicals. Ethyl acetate extract contains all the phytochemicals tested except glycosides and steroids. Whereas, the chloroform extract contains only alkaloids, flavonoids, glycosides and tannins other tested phytochemicals are absent. The presence of alkaloids, flavonoids and glycosides was observed in the hexane extract (Table 1). 
The antifungal activity of ethyl acetate, hexane, chloroform and methanol crude extracts of T. chebula dried fruits was possessed different degrees of activity against five Candidal strains, three Aspergillus species and three dermatophytic fungal strains. Methanol extract showed the highest activity (19.5 mm) against T. mentagrophytes, followed by ethyl acetate, chloroform and hexane. The mean zone of inhibition, MIC and MFC values are presented in (Tables 2 and 3). The least MIC and MFC values (62.5 and $125 \mu \mathrm{g} / \mathrm{ml}$ ) were observed against A. fumigatus and T. mentagrophytes. Among the four solvents, methanolic extracts showed significant antifungal activities. The positive control Amphotericin - B (100units/disc) for Yeast and Ketoconazole $(10 \mu \mathrm{g} / \mathrm{disc})$ for filamentous fungi showed inhibition zone ranges from 13.5 to $16.8 \mathrm{~mm}$ and 30.5 to $33.8 \mathrm{~mm}$ respectively. The negative control (10\% DMSO) showed no inhibition zone against the tested fungal strains.

Table 1: Phytochemical analysis of the different extracts of T. chebula dried fruits

\begin{tabular}{llcccc}
\hline S. No & Phytochemicals & Hexane & Chloroform & Ethyl acetate & Methanol \\
\hline 1 & Alkaloids & ++ & ++ & +++ & +++ \\
2 & Flavonoids & + & ++ & ++ & +++ \\
3 & Saponins & - & - & ++ & +++ \\
4 & Glycosides & + & + & - & +++ \\
5 & Tannins & - & ++ & ++ & +++ \\
6 & Terpenoids & - & - & ++ & +++ \\
7 & Steroids & - & - & - & +++ \\
\hline & -
\end{tabular}

\section{DISCUSSION}

Based on the presence of secondary metabolites, the medicinal plants were used to treat human ailments. Recently, traditional pharmacological and ethnomedical approaches were received great attention and recognition in modern medicine due to the prospective medicinal plants [15].

In this studies, antifungal activity of hexane, ethyl acetate, chloroform and methanol extracts of T. chebula dried fruit were tested. All the tested microbial strains showed varied degree of inhibitions. T. chebula dried fruit methanol extract exhibited good activity against T. mentagrophytes [Mean inhibition zone $(19.5 \mathrm{~mm})$, MIC $(62.5 \mu \mathrm{g} / \mathrm{ml})$ and MFC $(125 \mu \mathrm{g} / \mathrm{ml})]$ followed by ethyl acetate, chloroform and hexane extracts.

Aqueous extracts of T. chebula showed high antifungal activities whereas MIC and MFC values were found as $3.125 \mu \mathrm{g} / \mathrm{ml}$ and $12.5 \mu \mathrm{g} / \mathrm{ml}$ respectively.

T. chebula leaf extracts possessed antibacterial activities against four Gram positive bacterial strains such as Enterococcus faedalis, Bacillus subtillis, Corynebacterium, Staphylococcus aureus and three Gram-negative bacterial strains such as Klebsiella pneumonia, Shigella boydii and Salmonella typhi [17]. The aqueous extract of T. chebula showed antifungal activity against various dermatophytes and yeast (Floccosum, Tricophyton rubrum, Microsporum gypseum, Epidermophyton and C. albicans) $[18,19,20]$.

Table 2: Anticandidal activities of different crude extracts of Terminalia chebula dried fruits

\begin{tabular}{|c|c|c|c|c|c|c|c|}
\hline \multirow[t]{2}{*}{ S. No } & \multirow{2}{*}{$\begin{array}{l}\text { Candida sp. /Name of } \\
\text { the crude extracts }\end{array}$} & \multicolumn{4}{|c|}{ Mean zone of inhibition $(\mathrm{mm})^{a}$} & \multirow[t]{2}{*}{$\mathrm{MIC}(\mu \mathrm{g} / \mathrm{ml})$} & \multirow[t]{2}{*}{$\mathrm{MFC}(\mu \mathrm{g} / \mathrm{ml})$} \\
\hline & & $1000 \mu \mathrm{g} / \mathrm{disc}$ & $500 \mu \mathrm{g} / \mathrm{disc}$ & $250 \mu \mathrm{g} / \mathrm{disc}$ & Positive control & & \\
\hline \multirow[t]{5}{*}{1} & Candida albicans & & & & & & \\
\hline & Hexane & - & - & - & $14.8 \pm 0.76$ & ND & ND \\
\hline & Chloroform & $7.48 \pm 0.46$ & - & - & $14.8 \pm 0.76$ & ND & ND \\
\hline & Ethyl acetate & $8.47 \pm 0.50$ & - & - & $14.8 \pm 0.76$ & ND & ND \\
\hline & Methanol & $10.98 \pm 0.49$ & $8.49 \pm 0.48$ & - & $14.8 \pm 0.76$ & 250 & 500 \\
\hline \multirow[t]{5}{*}{2} & Candida glabrata & & & & & & \\
\hline & Hexane & - & - & - & $14.81 \pm 0.76$ & ND & ND \\
\hline & Chloroform & - & - & - & $14.79 \pm 0.76$ & ND & ND \\
\hline & Ethyl acetate & $8.00 \pm 0.50$ & - & - & $13.51 \pm 0.50$ & ND & ND \\
\hline & Methanol & $10.49 \pm 0.50$ & $7.51 \pm 0.50$ & - & $14.8 \pm 0.76$ & 250 & 500 \\
\hline \multirow[t]{5}{*}{3} & Candida tropicalis & & & & & & \\
\hline & Hexane & - & - & - & $14.79 \pm 0.76$ & ND & ND \\
\hline & Chloroform & - & - & - & $14.78 \pm 0.76$ & ND & ND \\
\hline & Ethyl acetate & - & - & - & $14.79 \pm 0.76$ & ND & ND \\
\hline & Methanol & $11.49 \pm 0.50$ * & $9.48 \pm 0.50$ & $7.49 \pm 0.50$ & $14.79 \pm 0.76$ & 250 & 500 \\
\hline \multirow[t]{5}{*}{4} & Candida parapsilosis & & & & & & \\
\hline & Hexane & - & - & - & $14.49 \pm 0.50$ & ND & ND \\
\hline & Chloroform & - & - & - & $14.81 \pm 0.76$ & ND & ND \\
\hline & Ethyl acetate & $8.53 \pm 0.50$ & - & - & $14.79 \pm 0.76$ & ND & ND \\
\hline & Methanol & $10.50 \pm 0.50$ & $7.51 \pm 0.50$ & - & $14.52 \pm 0.50$ & 250 & 500 \\
\hline \multirow[t]{5}{*}{5} & Candida krusei & & & & & & \\
\hline & Hexane & - & - & - & $15.79 \pm 0.76$ & ND & ND \\
\hline & Chloroform & $7.81 \pm 0.76$ & - & - & $14.83 \pm 0.76$ & ND & ND \\
\hline & Ethyl acetate & $9.51 \pm 0.50$ & $7.53 \pm 0.50$ & - & $16.81 \pm 0.76$ & ND & ND \\
\hline & Methanol & $12.49 \pm 0.50^{*}$ & $9.54 \pm 0.50$ & $7.51 \pm 0.50$ & $16.80 \pm 0.76$ & 250 & 500 \\
\hline
\end{tabular}

a-Mean of three replicates; \pm - Standard deviation; ND: not determined.

Positive control: Amphotericin-B (100 units/disc), ${ }^{*} p<0.05$ levels considered as significant 
Table 3: Antifungal activities of Terminalia chebula dried fruits different crude extracts

\begin{tabular}{|c|c|c|c|c|c|c|c|}
\hline \multirow[t]{2}{*}{ S. No } & \multirow{2}{*}{$\begin{array}{l}\text { Fungal sp./ } \\
\text { Name of the crude extracts }\end{array}$} & \multicolumn{4}{|c|}{ Mean zone of inhibition $(\mathrm{mm})^{\mathrm{a}}$} & \multirow[t]{2}{*}{$\mathrm{MIC}(\mu \mathrm{g} / \mathrm{ml})$} & \multirow[t]{2}{*}{$\mathrm{MFC}(\mu \mathrm{g} / \mathrm{ml})$} \\
\hline & & $1000 \mu \mathrm{g} / \mathrm{disc}$ & $500 \mu \mathrm{g} / \mathrm{disc}$ & $250 \mu \mathrm{g} / \mathrm{disc}$ & Positive control & & \\
\hline \multirow[t]{5}{*}{6} & Aspergillus niger & & & & & & \\
\hline & Hexane & $10.49 \pm 0.50$ & $7.51 \pm 0.50$ & - & $30.5 \pm 0.50$ & 250 & 500 \\
\hline & Chloroform & $11.50 \pm 0.50$ & $9.5 \pm 0.50$ & - & $32.5 \pm 0.50$ & 250 & 500 \\
\hline & Ethyl acetate & $14.71 \pm 0.64$ & $11.50 \pm 0.50$ & $9.51 \pm 0.50$ & $30.81 \pm 0.75$ & 250 & 500 \\
\hline & Methanol & $16.81 \pm 0.76$ & $14.49 \pm 0.50$ & $11.03 \pm 0.50$ & $30.53 \pm 0.50$ & 125 & 250 \\
\hline \multirow[t]{5}{*}{7} & Aspergillus flavus & & & & & & \\
\hline & Hexane & $12.51 \pm 0.50$ & $10.49 \pm 0.50$ & $8.80 \pm 0.76$ & $31.51 \pm 0.50$ & 250 & 500 \\
\hline & Chloroform & $14.49 \pm 0.50$ & $11.01 \pm 0.50$ & $9.03 \pm 0.50$ & $31.80 \pm 0.76$ & 250 & 500 \\
\hline & Ethyl acetate & $15.79 \pm 0.76$ & $13.52 \pm 0.50$ & $10.49 \pm 0.50$ & $30.51 \pm 0.50$ & 250 & 500 \\
\hline & Methanol & $18.50 \pm 0.50$ * & $15.81 \pm 0.76$ & $13.48 \pm 0.50$ & $31.50 \pm 0.50$ & 62.5 & 125 \\
\hline \multirow[t]{5}{*}{8} & Aspergillus fumigates & & & & & & \\
\hline & Hexane & $12.99 \pm 0.50$ & $10.99 \pm 0.50$ & $9.51 \pm 0.50$ & $30.51 \pm 0.50$ & 250 & 500 \\
\hline & Chloroform & $14.83 \pm 0.76$ & $12.51 \pm 0.50$ & $10.52 \pm 0.50$ & $31.52 \pm 0.50$ & 250 & 500 \\
\hline & Ethyl acetate & $16.52 \pm 0.50$ & $13.53 \pm 0.50$ & $11.83 \pm 0.76$ & $30.53 \pm 0.50$ & 125 & 250 \\
\hline & Methanol & $18.50 \pm 0.50$ * & $15.50 \pm 0.50$ & $13.51 \pm 0.50$ & $30.81 \pm 0.76$ & 62.5 & 125 \\
\hline \multirow[t]{5}{*}{9} & Trichophyton rubrum & & & & & & \\
\hline & Hexane & $11.99 \pm 0.50$ & $9.53 \pm 0.50$ & $7.54 \pm 0.50$ & $32.81 \pm 0.76$ & 250 & 500 \\
\hline & Chloroform & $13.51 \pm 0.50$ & $11.03 \pm 0.50$ & $9.55 \pm 0.50$ & $32.52 \pm 0.50$ & 250 & 500 \\
\hline & Ethyl acetate & $16.83 \pm 0.76$ & $14.51 \pm 0.50$ & $11.03 \pm 0.50$ & $30.53 \pm 0.50$ & 125 & 250 \\
\hline & Methanol & $17.71 \pm 0.64$ & $15.53 \pm 0.50$ & $12.54 \pm 0.50$ & $30.84 \pm 0.76$ & 125 & 250 \\
\hline \multirow[t]{5}{*}{10} & Trichophyton mentagrophytes & & & & & & \\
\hline & Hexane & $13.54 \pm 0.50$ & $11.01 \pm 0.50$ & $9.54 \pm 0.50$ & $33.51 \pm 0.50$ & 250 & 500 \\
\hline & Chloroform & $15.04 \pm 0.50$ & $13.52 \pm 0.50$ & $11.01 \pm 0.50$ & $33.81 \pm 0.76$ & 250 & 500 \\
\hline & Ethyl acetate & $17.73 \pm 0.64$ & $14.51 \pm 0.50$ & $11.02 \pm 0.50$ & $32.51 \pm 0.50$ & 125 & 250 \\
\hline & Methanol & $19.51 \pm 0.50 *$ & $16.52 \pm 0.50$ & $14.54 \pm 0.76$ & $32.81 \pm 0.76$ & 62.5 & 125 \\
\hline \multirow[t]{5}{*}{11} & Microsporum gypseum & & & & & & \\
\hline & Hexane & $12.03 \pm 0.50$ & $9.01 \pm 0.50$ & $7.52 \pm 0.50$ & $32.81 \pm 0.76$ & 250 & 500 \\
\hline & Chloroform & $13.74 \pm 0.64$ & $11.51 \pm 0.50$ & $9.81 \pm 0.76$ & $32.53 \pm 0.50$ & 250 & 500 \\
\hline & Ethyl acetate & $15.52 \pm 0.50$ & $13.52 \pm 0.50$ & $11.02 \pm 0.50$ & $32.51 \pm 0.50$ & 250 & 500 \\
\hline & Methanol & $17.71 \pm 0.64$ & $14.51 \pm 0.51$ & $11.51 \pm 0.50$ & $31.83 \pm 0.76$ & 125 & 250 \\
\hline
\end{tabular}

a-Mean of three replicates; ND: not determined; Positive control: Ketaconazole $(10 \mu \mathrm{g} / \mathrm{disc}) ;{ }^{*} p<0.05$ level

In this study, methanol extract of T. chebula showed highest mean of inhibition zone $(19.5 \mathrm{~mm})$, lowest MIC and MFC (62.5 and $125.0 \mu \mathrm{g} / \mathrm{ml}$ ) values against A. fumigatus and T. mentagrophytes. Similarly, Fyhrquist et al. [21] reported the methanol extract of the leaf and roots of T. sericea and T. sambesiaca contains strong antifungal properties against C. albicans. Moreover, the methanol extract of Diospyros virginiana reported the presence of phenol compound which showed strong antibacterial and antifungal activities against Enterobacter cloacae, E. coli, P. aeruginosa, S. typhimurium, B. cereus, Listeria monocytogenes, Micrococcus flavus and S. aureus and A. fumigatus, A. versicolor, A. ochraceus, A. niger, Trichoderma viride, Penicillium funiculosum, P. ochrochloron and P. var. cyclopium [22]. Rathinamoorthy and Thilagavathi described the methanol extract of T. chebula fruits showed antibacterial activity against Bacillus licheniformis MTCC 429), and Corynebacterium acnes (MTCC 151), Micrococcus luteus (ATCC 49732) and Corynebacterium sp. (MTCC 8730).

In the present investigation, the methanol extract of T. chebula fruit possessed antifungal activity against few Aspergillus species, Candida species and Dermatophytic strains than other solvent extracts like hexane, chloroform and ethyl acetate which was similar to the previous report [23]. The methanol extract of Gnaphalium polycaulon leaf exhibited high antifungal activity against Aspergillus flavus, A. fumigates, A. oryzae, Candida albicans and Penicilium notatum.
Methanol extract of T. chebula showed potent inhibitory zone on tested fungal strains. Methanol solvent is known for its ability to isolate more antimicrobial compounds from plants including tannins, quassinoids, polyphenols, saponins, xanthoxyllines, lactones, terpenoids, totarol, phenones and flavones whereas water extracts showed terpenoids, starches, polypeptides, saponins, anthocyanins, tannins and lectins [24]. Various results confirmed that among the tested four solvents, methanol showed better results on antimicrobial substance extraction from medicinal plants $[25,26,27]$.

In this study, methanol estract of T. chebula dried fruits showed highest antifungal activity due to their alkaloids, glycosides, saponins, tannins, flavonoids, terpenoids and steroids. In plants, alkaloids, tannins, flavonoids and many aromatic compounds or secondary metabolites which is involved in defense mechanism against invading microorganisms and various predators like herbivores and insects [28]. Similar results reported on $600 \mu \mathrm{g} / \mathrm{ml}$ of ripened T.chebula fruits extracts against T. mentagrophytes [29]. The results of the present study evident the importance of T. chebula dried fruit extracts against various fungal pathogens. Further study on the isolation antifungal molecule and it's characterization from the methanol extract of T. chebula dried fruits are under process. 


\section{ACKNOWLEDGEMENT}

We would like to express our thanks to Head of the Department, Plant Biology and Plant Biotechnology, Presidency College (Autonomous), Chennai, Tamilnadu, India for the facilities provided to carry out the study.

\section{REFERENCES}

1. Desta B, Ethiopian traditional herbs. Part II. Antimicrobial activity of 63 medicinal plants. Journal of Ethnopharmacology. 1993; 39:263-276.

2. Caceres A, Fletes L, Aguilar L, Ramirez O, Ligia F, Tareena AM. Plants used in guatemala for the treatment of gastrointestinal disorders. Confirmation of activity against Enterobacteriaceae. Journal of Ethnopharmacology. 1993;38:31-38.

3. Douglas LJ. Candida biofilms and their role in infection. Trends in Microbiology. 2003; 11: 30-36.

4. Stevens DA. Fungal infections in AIDS patient. British Journal of Clinical practice. 1990;71:11-22.

5. Denning DW. Invasive aspergillosis. Clinical Infectious Diseases. 1998; 26:781-803

6. Blanco JL, Garcia ME. Immune response to fungal infections, Veterinary Immunology and Immunopathology. 2008;125:47-70.

7. Arias CA, Murray BE. Antibiotic-resistant bugs in the 21 st century e a clinical super-challenge. New England Journal of Medicine. 2009;360:439-443.

8. Fogliani B, Raharivelomanana P, Bianchini JP, Bouraima-Madjebi S, Hnawia E. Bioactive ellagitannins from Cunonia macrophylla, an endemic Cunoniaceae from New Caledonia, Phytochemicals. 2005; $66: 241-247$

9. Rao NK, Nammi S. Antidiabetic and renoprotective effects of the chloroform extract of Terminalia chebula Retz. Seeds in streptozotocin-induced diabetic rats. BMC Complementary Medicine and Therapies. 2006;6:17-22

10. Saleh HH, Rashad H, Khafaga S. Pharmacological action of Terminalia chebula. Journal of the Egyptian Medical Association. 1952;35:763771.

11. Harbone JB. Methods of extraction and isolation. Phytochemical methods. 3rd ed. Chapman and Hall: London; 1998.

12. Bauer AW, Kirby WMM, Scherris JC, Turck M. Antibiotic Susceptibility testing by a standardized single disc method. American Journal of Clinical Pathology. 1966; 45: 493-496.

13. Clinical and Laboratory Standards Institute. Reference Method for Broth Dilution Antifungal Susceptibility Testing of Yeasts; Approved Standard, CLSI Document M27-A3. 3rd ed. Clinical Laboratory Standards Institute, Wayne, PA, USA; 2008a.

14. Clinical and Laboratory Standards Institute. Reference Method for Broth Dilution Antifungal Susceptibility Testing of Filamentous Fungi;
Approved Standard, CLSI Document M38-A2. 2nd ed. Clinical and Laboratory Standards Institute, Wayne, PA, USA; 2008b.

15. Upadhay B, Sing KP, Kumar A. Ethano-medicinal, phytochemical and antimicrobial studies of Euphorbia tirucalli. Journal of Phytological Research. 2010;2:65-77.

16. Rubini B, Shanthi G, Soundhari C, Rajarajan S. Antifungal activity of Terminalia chebula and Terminalia catappa on two dermatophytes. Open Access Journal of Medicinal and Aromatic Plants. 2013;4(2):15-19

17. Kathirvel A, Sujatha V. In vitro assessment of antioxidant and antibacterial properties of Terminalia chebula Retz. Leaves. Asian Pacific Journal of Tropical Biomedicine. 2012;788-795.

18. Chattopadhyay RR, Bhattacharyya SK. Plant Review Terminalia chebula. Pharmacognosy Review. 2007; 23:145-155.

19. Anil M, Nandini P. Simultaneous isolation and identification of phytoconstituents from Terminalia chebula by preparative chromatography. Journal of Chemical and Pharmaceutical Research. 2010; 2(5):97-103

20. Kirtikar KR, Basu BD. Indian Medicinal Plants. $2^{\text {nd }}$ ed. Dehli: Periodical Experts; 1993

21. Fyhrquist $P$, Mwasumbi $L$, Haeggstrom CA, Vuorela $H$, Hiltunen $R$, Vuorela P. Ethnobotanical and antimicrobial investigation on some species of Terminalia and Combretum (Combretaceae) growing in Tanzania. Journal of Ethnopharmacology. 2002;79:169-177.

22. Rashed K, Ciric A, Glamoclija J, Sokovic M. Antibacterial and antifungal activities of methanol extract and phenolic compounds from Diospyros virginiana L. Industrial Crops and Products. 2014;59:210-215.

23. Sofowora A. Medicinal Plants and Traditional in Africa. Chichester John Wiley and sons. Newyork:1993.

24. Cowan MM. Plants products as antimicrobial agents. Clinical Microbiology Reviews. 1999:12:564-582

25. Ahmad I, Mahmood Z, Mohammad F. Screening of some Indian medicinal plants for their antimicrobial properties. Journal of Ethnopharmacology. 1998;62:183-193

26. Rathinamoorthy R, Thilagavathi G. Statistical optimization of Terminalia chebula fruit extraction for improved antibacterial activity against odour-casusing bacteria. Proceedings of the National Academy of Sciences, India, Section B: Biological Sciences. 2020;90:365-374.

27. Kaminidevi S, Thangavelu T, Udayabhanu J, Thangavel SM. Antimicrobial activity of methanolic extracts of indigenous traditional Indian folk Medicinal Plant, Gnaphalium polycaulon. International Journal of Green Pharmacy. 2015; 9:39-44.

28. Lin J, Opoku R, Geheeb-Keller M, Hutchings AD, Terblanche SE, Jager AK, Van Staden J. Preliminary screening of some traditional zulu medicinal plants for anti-inflammatory and antimicrobial activities. Journal of Ethnopharmacology. 1999:68:267-274.

29. Rajarajan S, Selvi RM. Estimation of extract from the ripe fruit unripe fruit and leaf galls of Terminalia chebula (chebulic myrobalan). Biomedicine TTT. 2004;24: 7-11. 